\title{
O desenvolvimento e o fracasso do método sintático carnapiano
}

\section{The development and failure of the syntactic carnapian method}

\author{
PEDRO HENRIQUE NOGUEIRA PIZZUTTI ${ }^{1}$
}

\begin{abstract}
Resumo: Este trabalho tem por objetivo apresentar o método sintático de Carnap, para análise da linguagem científica, no The logical syntax of language e o seu possível fracasso. O método consiste na elaboração de uma teoria lógico-linguística, a sintaxe lógica, para lidar com estruturas linguísticas no nível sintático. A sintaxe lógica é a proposta de Carnap e a formulação desta é feita por meio da sintaxe de duas linguagens artificialmente construídas, as Linguagens I e II, e a tentativa de uma Sintaxe Geral aplicável a qualquer linguagem. Com a construção de L.I, Carnap mostrou ser possível formular a sintaxe lógica de uma linguagem valendo-se da própria linguagem objeto. Em L.II, introduziu regras indefinidas de transformação para elaboração de um critério completo de validade para as sentenças da Matemática. Na discussão da Sintaxe Geral, considerou regras físicas de transformação para uma linguagem sintática. Contudo, ao tentar formular a definição de analiticidade na Linguagem II, Carnap teve que admitir a impossibilidade de construir a definição de "analítico" com base nos recursos de L.II Contrariando os resultados obtidos com L.I, não é possível formular completamente a sintaxe de uma linguagem mais rica com base apenas nos recursos linguísticos de si mesma. Além deste problema, a construção de "analítico em II", em uma metalinguagem mais rica, utilizou um método semântico. Tanto o apelo a uma metalinguagem mais rica, quanto o recurso a um método semântico, minam o projeto puramente sintático de Carnap.
\end{abstract}

Palavras-chave: Método sintático. Analítico. Logical syntax. Rudolf Carnap. Fracasso.

Abstract: This paper aims to present the syntactic method of Carnap, for analysis of scientific language, in The logical syntax of language and its possible failure. The method consists in the elaboration of a logic-linguistic theory, the logical syntax, to deal with linguistic structures at the syntactic level. The logical syntax is the proposal of Carnap and the formulation of this is made through the syntax of two languages artificially constructed, Languages I and II, and the attempt of a General Syntax applicable to any language. With the construction of L.I Carnap showed that it is possible to formulate the logical syntax of a language using the object language itself. In L.II, he introduced indefinite rules of transformation to elaborate a complete criterion of validity for the sentences of Mathematics. In the discussion of General Syntax, he considered physical rules of transformation for a syntactic language. However, in attempting to formulate the definition of analyticity in Language II, Carnap had to admit the impossibility of constructing the definition of "analytic" on the basis of L.II's resources. Contrary to the results obtained with $\mathrm{LI}$, it is not possible to formulate the syntax of a richer language based only on the linguistic resources of itself. In addition to this problem, the construction of "analytic in II", in a richer metalanguage, used a semantic method. Both the appeal to richer metalanguage and the use of a semantic method undermine the purely syntactic design of Carnap.

Keywords: Syntactic method. Analytical. Logical syntax. Rudolf Carnap. Failure.

\section{Introdução}

\footnotetext{
${ }^{1}$ Mestrando em Filosofia pela Universidade Estadual de Londrina, graduado em Licenciatura em Filosofia pela mesma universidade (2018). E-mail: pedropizzutti@gmail.com.
} 
No presente trabalho apresentaremos o método sintático de análise lógica da linguagem científica, elaborado por Carnap, em The logical syntax of language ${ }^{2}$ (2017), e seu possível fracasso. Para esta análise, reconstruiremos as linhas gerais do projeto, especialmente no que tange ao conceito de analiticidade, e mostraremos os problemas e os limites do método puramente sintático de Carnap em 1934.

O movimento do Empirismo Lógico defendeu a ideia de que a Filosofia não tem um ponto privilegiado que a permite se colocar acima, ou mesmo lado a lado, com as ciências. A Filosofia é concebida antes como aquela que deve se reorientar conforme os resultados e avanços estabelecidos pelas ciências especiais. Diante disto, a pergunta que fica é: Qual é a tarefa da Filosofia e qual relação ela mantém com o empreendimento científico?

Os empiristas lógicos, em sua maioria, rejeitaram uma concepção naturalista em que a Filosofia era vista simplesmente como uma ciência empírica entre as outras, tal como um ramo da Psicologia ou da Sociologia do Conhecimento, por exemplo. De modo geral, e pelo contrário, eles concebiam a Filosofia como um braço da Lógica e defendiam que a tarefa especificamente filosófica era a de análise lógica das ciências especiais (FRIEDMAN, 1991, p. 515).

Contudo, Michael Friedman, em The re-evaluation of logical positivism (1991), afirma que a perspectiva e o modo como tal análise deveria ocorrer se manteve nebulosa até a aparição do Logical syntax de Carnap, originalmente publicado em 1934. É justamente neste texto que Carnap desenvolve seu método sintático. Em sua Intellectual autobiography (1963, p. 55), o autor narra que as discussões no Círculo de Viena, conforme tentavam formular mais precisamente os problemas filosóficos que estavam interessados, acabavam sempre por discutir problemas de análise lógica da linguagem científica. Carnap nos conta que foi o desejo de construir um framework para executar e mostrar os resultados desta análise a grande motivação para o desenvolvimento do método sintático. Não obstante, tendo isto posto, nosso objetivo consiste em: considerar a elaboração do método sintático como uma ferramenta para análise metateórica da Ciência e o seu possível fracasso.

\section{O método sintático e as dificuldades impostas pelo conceito de analiticidade}

Em Logical syntax, Carnap defende que a única parte científica de qualquer trabalho filosófico é a de análise lógica. Buscando a expressão e formulação de forma rigorosa desta análise, Carnap propõe o método sintático. Seu método é o da sintaxe lógica que, por sua vez, tem por objetivo a constituição de uma linguagem, um framework, que permita justamente a expressão e formulação das análises da linguagem científica. Por conseguinte, o que cabe à Filosofia é a análise lógica das sentenças e conceitos das ciências, o que Carnap chamou de Lógica da Ciência.

\footnotetext{
${ }^{2}$ Doravante, Logical syntax.
} 
Identificando Lógica da Ciência com sintaxe lógica, essa é quem substitui a Filosofia em seu sentido tradicional (CARNAP, 2017, p. xiii).

Carnap considera a sintaxe lógica como uma teoria formal acerca das formas linguísticas de uma linguagem. A teoria procura formular regras formais que regem uma linguagem e as consequências que derivam destas regras. A formalidade das regras, definições e da própria teoria, decorre delas não fazerem nenhuma referência ao significado dos símbolos, aos sentidos das expressões ou aos falantes. Portanto, a teoria é formal porque faz referência única e exclusivamente aos tipos, estrutura e ordenação dos símbolos (CARNAP, 2017, p.1). Em resumo, pode-se dizer que a função da sintaxe lógica é dar regras de construção e dedução de sentenças, tendo uma linguagem qualquer de referência, através de arranjos simbólicos sem nenhuma atribuição extralinguística (PEREIRA, 2013, p. 36).

Para a construção de uma sintaxe lógica, são necessárias, ao menos em princípio, duas linguagens, a saber, a linguagem objeto e a metalinguagem ${ }^{3}$. A primeira é a linguagem que é o objeto de investigação, é para ela que se propõe a formulação de sua sintaxe; a segunda é a linguagem que utilizamos para falar das formas sintáticas da linguagem objeto escolhida (CARNAP, 2017, p. 4). Na construção feita por Carnap, há a utilização de duas linguagens simbólicas, as chamadas Linguagem I e II [L.I e L.II], como linguagens objeto e, como metalinguagem, em um primeiro momento, a língua inglesa com a adição de símbolos góticos.

De modo geral, considerado do ponto de vista sintático, isto é, quando o interesse é apenas a estrutura formal da linguagem, toda linguagem é interpretada como um cálculo. As regras de um cálculo determinam apenas em que circunstâncias uma sequência de símbolos forma uma expressão e sob quais condições é possível transformar uma expressão em outra. Deste modo, um cálculo contém apenas um vocabulário (os símbolos) e uma sintaxe (as regras de formação e transformação) ${ }^{4}$ (PEREIRA, 2013, p. 37-38).

De modo específico, há uma distinção entre sintaxe pura e descritiva. A pura tem por referência padrões simbólicos de uma linguagem, sem levar em conta se de fato existe uma linguagem para qual aquela seria sua sintaxe. Por sua vez, a descritiva diz respeito às estruturas, propriedades e relações de expressões, sentenças e linguagens, que são empiricamente dadas, isto é, com as expressões de um livro de literatura em língua portuguesa ou as de uma teoria científica como a da Relatividade Geral de Einstein, por exemplo (CARNAP, 2017, p. 6-7).

\footnotetext{
${ }^{3}$ Embora Carnap tenha se referido a esta como linguagem sintática, seu termo não ficou consagrado para a literatura. Por conta disso, adotamos o termo metalinguagem, que não só é o correspondente para a ideia carnapiana, mas é amplamente reconhecido.

${ }^{4}$ É importante ressaltar que Carnap atribui o status de cálculo apenas à parte sintática de uma linguagem, ou seja, não há a defesa da ideia de que linguagens são meramente cálculos. Cf. Carnap, 2017, p. 5 .
} 
Assim, a construção da sintaxe lógica é a formulação de um framework lógico que permite uma correlação com a linguagem científica; onde a análise lógica se torna, além de possível, formalmente rigorosa. Não obstante, esta construção é livre e nunca absoluta, sendo sempre relativa a uma linguagem. A posição de Carnap quanto a isso é bem clara no princípio de tolerância linguístico:

Não é nosso trabalho estabelecer proibições, mas chegar a convenções [...]. Em lógica, não há moral. Cada um é livre para construir sua própria lógica, isto é, sua própria forma de linguagem, como quiser. Tudo que é requerido deste é que, se desejar discutir esta, deve expor seus métodos claramente e dar regras sintáticas ao invés de argumentos filosóficos. (CARNAP, 1937, p. 51-52, itálico do autor).

No texto do Logical syntax, o método sintático é elaborado junto a construção de duas linguagens artificiais, as já referidas L.I e L.II, e, por fim, há um esboço de uma Sintaxe Geral. A construção de L.I não é muito diferente do que um estudante vê em um curso de Lógica Simbólica. Primeiro se fixam os símbolos, depois regras de formação para constituição de fórmulas e, por último, a parte dedutiva do cálculo, isto é, as regras de transformação. Construída por meio de regras definidas de transformação, L.I contém uma linguagem formal básica, capaz de elaborar apenas uma aritmética elementar dos números naturais até o limite das suas regras definidas de transformação (CARNAP, 2017, p. 11; PEREIRA, 2013, p. 40). Se considerar o objetivo de análise lógica da linguagem científica, L.I tem a seu favor o fato de ser definida, mas pesa contra si o fato de ser muito simples e fraca.

Já L.II é muito mais rica linguisticamente, possui a própria L.I como uma sublinguagem, contém conceitos indefinidos, a aritmética dos números reais e a análise matemática construída com base na Aritmética Clássica. Não obstante, L.II compreende toda a Matemática Clássica, desde funções com argumentos reais até o cálculo infinitesimal, além da teoria dos conjuntos (CARNAP, 2017, p. 83; PEREIRA, 2013, p. 40). A grande vantagem de L.II, é que nela é possível uma sintaxe descritiva, assim, para além das expressões da Lógica e da Matemática, ela permite a construção de sentenças empíricas de qualquer domínio de objetos, sejam sentenças da Física Clássica, sejam da Relatividade Geral (CARNAP, 2017, p. 11).

Posterior às discussões envoltas nas Linguagens I e II, Carnap direcionou a pesquisa para a construção de uma Sintaxe Geral. A ideia era elaborar um sistema de definições de termos e conceitos sintáticos tão amplos e compreensíveis que estes seriam aplicáveis a toda e qualquer linguagem (CARNAP, 2007, p. 167). Com esta sintaxe, haveria uma teoria geral acerca da manipulação simbólica. Por meio desta teoria, seria possível estabelecer as regras de articulação simbólica quanto à construção de sentenças e, consequentemente, o framework necessário para análise 
das relações lógico-linguísticas entre estas sentenças estaria construído (PEREIRA, 2013, p. 40-41).

A principal preocupação de Carnap, ao discutir a sintaxe lógica com a elaboração da Linguagem I, foi mostrar como seria possível estabelecer a metalinguagem, de uma linguagem objeto, se valendo apenas do recurso expressivo da própria linguagem objeto. O problema que Carnap tinha em vistas era a suspeita de que, com a necessidade de sempre se recorrer a uma metalinguagem outra, haveria um recorrer ad infinitum a metalinguagens. O recurso que Carnap utiliza para a construção da metalinguagem de L.I, com os recursos da própria L.I, é o método de aritmetização de sintaxes desenvolvido por Gödel. Sem entrar em detalhes, Gödel demonstrou que qualquer sistema linguístico que consiga elaborar a aritmética dos números naturais possui também os recursos para expressar, ao menos em partes, sua própria sintaxe (TRANJAN, 2010, p. 196).

Já com a construção de L.II, Carnap introduziu a possibilidade de regras indefinidas de transformação, o intento dessa mudança era dar ao método sintático a possibilidade de formulação de um critério completo de validade para as sentenças da Matemática. Para Tranjan, Carnap tinha, como pano de fundo, a tentativa de dar uma possível resposta ao problema posto pelo teorema de incompletude de Gödel. Este, de modo geral, havia provado que qualquer sistema formal baseado em regras definidas de transformação era incapaz de demonstrar a verdade do conjunto das sentenças da Aritmética (TRANJAN, 2010, p. 204). Com o método-c, ou método baseado no conceito de consequência lógica, Carnap introduziu regras indefinidas para sistemas formais e, com isso, elaborou uma forma de estabelecer com completude quais sentenças são logicamente determinadas e quais são sintéticas (CARNAP, 2017, p. 100-101).

Por fim, com a discussão da Sintaxe Geral, Carnap propôs, para além das regras lógicas indefinidas de transformação, regras físicas. Estas regras permitiriam adicionar aos axiomas da sintaxe lógica da linguagem objeto leis da natureza, por exemplo. A admissão deste tipo de regra possibilita a construção e análise de teoria científicas de acordo com a received view. A progressividade que há na construção do método sintático no texto do Logical syntax, torna este amplo e robusto o suficiente para lidar com uma análise lógica da linguagem científica das ciências empíricas. Contudo, apesar das inovações e do aparente sucesso, há alguns problemas graves no método. Uma inspeção acerca do conceito de analiticidade mostra os candidatos a Calcanhar de Aquiles da teoria sintática carnapiana.

Diante da tese ousada, defendida por Carnap, de que as únicas sentenças significativas são analíticas ou sintéticas, Cirera (1994, p. 246) sustenta que um dos pontos altos do Logical syntax é a caracterização exata da noção de "analítico". Porém, apesar do fato das definições carnapianas serem, de fato, bastante precisas, existem algumas possíveis dificuldades que as circundam: a primeira é que não há 
uma definição absoluta do termo analítico; a segunda é a necessidade de recorrer a uma metalinguagem mais rica para estabelecer a definição; a terceira é que o método utilizado para construir a definição não é sintático, mas semântico.

O fato de Carnap nunca dar uma definição absoluta do conceito "analítico" pode pesar contra ele, afinal, ao relativizar o conceito sempre a uma linguagem, pode-se pensar que nossa noção intuitiva não é contemplada. Entretanto, antes de pesar contra Carnap, a relativização permite uma defesa deste frente a crítica feita por Quine em "Dois dogmas do empirismo" (2011). Neste texto, Quine defende uma rejeição da distinção analítico-sintético como o fundamento para epistemologia, ou quiçá, como uma distinção absoluta em epistemologia.

Para Tranjan, a interpretação quineana está completamente equivocada quanto a ideia carnapiana. A distinção feita em Logical syntax entre os termos "analítico" e "sintético" não é de cunho epistemológico, mas sintático. As razões apresentadas por Tranjan são duas: (i) o fundamento da caracterização não é epistemológico, as definições elaboradas se baseiam apenas em condições combinatórias de símbolos e não em alguma condição epistemológica; (ii) o próprio significado das definições não é epistemológico, o que Carnap pretende não é apresentar as condições epistemológicas onde sentenças devem ser vistas como empíricas ou não, mas apenas certas características entre tipos diferentes de sentenças em uma linguagem formalizada (TRANJAN, 2010, p. 233).

A referência para a construção dos conceitos sintáticos são certas noções intuitivas, e as razões podem ser epistemológicas, mas o esforço é para tornar estas distinções e definições mais exatas conforme elas são elaboradas dentro de um framework formalmente rigoroso como o da análise sintática. As construções dessas noções, por parte do Carnap, nunca são dogmatizadas, mas sempre relativizadas a uma linguagem. O referencial é uma linguagem entre muitas possíveis. O conceito de analiticidade é elaborado de forma que uma sentença é verdadeira apenas em virtude das regras de formação e transformação. Devido ao fato dessas regras serem convencionais, em princípio, não é sequer possível dar uma definição absoluta do que precisamente significaria uma sentença ser analítica em uma linguagem (CIRERA, 1994, p. 248). Antes de representar um defeito, a relativização feita por Carnap apresenta um progresso nas investigações acerta da distinção analíticosintético. Porém, outros problemas se colocam.

Duas questões movem Carnap ao discutir a definição do conceito "analítico em L.II", sendo elas: (i) é possível traduzir a definição de "analítico em II" em uma metalinguagem estritamente formal?; (ii) a própria Linguagem II pode ser usada como esta metalinguagem? A primeira recebe uma resposta afirmativa, enquanto a segunda uma negativa. Carnap assevera que para qualquer linguagem $S$, se ela não for contraditória, a definição de "analítico em S" não pode ser formulada com base em uma metalinguagem construída a partir de S (CARNAP, 2017, p. 113). 
Na seção 6o do Logical syntax, Carnap pretende demonstrar a verdade da afirmação anterior e, para isso, constrói uma versão da Antinomia do Mentiroso com base apenas em termos sintáticos. Por conta da capacidade sintática de autoreferência, advinda da construção da metalinguagem a partir da linguagem objeto, o teorema 6oc. I. afirma que: "Se S é consistente, ou, ao menos, não contraditória, então 'analítico (em S)' é indefinível em S” (CARNAP, 2017, p. 219, itálico do autor). A conclusão é de que só é possível definir o termo "analítico em S" em uma metalinguagem mais rica que a própria linguagem $\mathrm{S}$.

Pereira (2013, p. 70) considera a necessidade de uma metalinguagem distinta da linguagem objeto, um ponto que suplanta o projeto puramente sintático de Carnap. Seu argumento é que devido a uma hierarquia entre linguagens, decorrente da necessidade de uma metalinguagem mais rica, há referências extralinguísticas à linguagem objeto, o que arruína o projeto puramente sintático. Além disso, Carnap afirmou que, tomando a linguagem científica como linguagem objeto, a construção da sintaxe desta, com recursos apenas de si mesma, mostraria que a sintaxe lógica forma um único sistema com a Ciência, isto por meio de uma única linguagem (CARNAP, 2017, p. 286). Deste modo, a inevitabilidade de uma metalinguagem mais rica acaba por dificultar o projeto de uma unidade científica entre linguagem da Ciência e sintaxe lógica.

Há ainda mais um fator que mina o projeto puramente sintático de Carnap. Quando definiu as regras de consequência para a L.I, Carnap primeiro estipulou uma definição para o termo "consequência”, através de regras de inferência, e só então, com base nestas, deu definições para os termos "analítico" e "contraditório". Mas, quando formulou regras de consequência para L.II, Carnap inverte e primeiro dá definições dos termos "analítico" e "contraditório" para que, com eles, formule a definição de consequência.

Tranjan nota que esta inversão faz Carnap elaborar a definição com uma estrutura teórica muito semelhante a que Tarski apresenta ao dar uma definição de verdade em "O conceito de verdade em linguagens formalizadas" (2007). Sem entrar nos detalhes técnicos, a definição de Carnap pretende fazer o mesmo, e pelos mesmos métodos, que faria uma definição de Tarski para o termo "verdade em L.II". Embora haja um grande mérito técnico e teórico em sua elaboração de analiticidade para a Linguagem II, Carnap "trapaceou”, deu uma definição de "analítico em II" e trabalhou retrocedendo. $\mathrm{O}$ fim desse processo é a definição de "consequência" que, para Carnap (2017, p. 168), deveria ser o começo de toda sintaxe, mas que, pelo modo construído, nada tem de sintática (TRANJAN, 2010, p. 246-247). O conceito de analiticidade, tão fundamental e crucial para o método sintático, se torna seu Calcanhar de Aquiles:

A situação, então, pode ser sumariada assim: Para realizar uma das tarefas lógicas mais importantes de seu livro (a circunscrição da 
matemática clássica por meio de um sistema lógico-formal), justamente aquela tarefa que o motivara a introduzir um novo método sintático indefinido como base da lógica formal, Carnap utiliza um procedimento que perde qualquer conteúdo sintático, e que hoje é descrito unanimamente como um procedimento semântico. (TRANJAN, 2010, p. 247-248, itálico do autor).

\section{Considerações finais}

A discussão em torno do termo "analítico" mostra o fracasso do método sintático. Este não apresenta a capacidade que Carnap colocava sobre ele. Não foi possível construir a analiticidade em uma metalinguagem com os recursos linguísticos da própria linguagem objeto e não foi viável a elaboração de uma circunscrição puramente sintática da Matemática Clássica. Assim, pode-se sumarizar os fracassos do método sintático em: (i) impossibilidade de dar uma definição para o conceito "analítico" em uma metalinguagem baseada nos recursos de sua linguagem objeto; (ii) definição de "analítico em II", valendo-se de uma metalinguagem mais rica, utiliza um método semântico.

Embora, de modo evidente, o método sintático de Carnap não atinja seus objetivos, cabe ressaltar que o seu fracasso é imposto pelos critérios e demandas colocadas pelo próprio Carnap. Pode-se dizer que o autor esperava demais de seu constructo. É preciso notar, por exemplo, que a definição do termo "analítico em II" é feita de um modo formal bastante preciso, o único problema é que este método é semântico e não sintático. Não há um fracasso em fornecer uma definição formal da analiticidade, mas "apenas" uma definição sintática.

Por estes fatores, e outros, como o sucesso do método semântico nas mãos de Tarski, que em sua Intellectual autobiography, Carnap admitiu que uma das principais teses do Logical syntax foi elaborada de maneira equivocada. A tese que o autor se refere é a de que todos os problemas da Filosofia da Ciência seriam problemas sintáticos. Em detrimento dessa visão muito restritiva, Carnap argumenta que deveria ter formulado a tese de que tais problemas são metateóricos. Por conseguinte, a metateórica científica deveria incluir a semântica e até mesmo a pragmática (CARNAP, 1963, p. 56). Este é um dos fatores que explica o abandono rápido do método sintático em direção a uma complementação semântica para análise lógica da linguagem científica na obra de Rudolf Carnap.

\section{Referências}

AYER, A. J. Logical positivism. USA, New York: The Free Press, 1959.

AWODEY, S. Carnap's quest for analyticity: the studies in semantics. In: (Friedman \& Creath, 2007), 2007.

BRANQUINHO, J.; MURCHO, D.; GOMES, N. G. Enciclopédia de termos lógico-filosóficos. São Paulo: Martins Fontes, 2006. 
CARNAP, R. "Intellectual Autobiography”. In: Schilpp, P.A. (ed.). The philosophy of Rudolf Carnap. La Salle: Open Court, 1963.

CIRERA, R. Carnap and the Vienna circle. Translated by Dick Edelstein. Amsterdam:

Editions Rodopi B.V, 1994.

The logical syntax of language. London: Routledge \& Kegan Paul. Reprinted in India: Facsimile Publisher, 2017.

FAJARDO, R. A. S. Lógica matemática. São Paulo: Editora da Universidade de São Paulo, 2017.

FEIGL, H. A visão “ortodoxa” de teorias: comentários para defesa assim como para crítica. Tradução de Osvaldo Pessoa Júnior. Scientiae studia. São Paulo, Vol. 2, 2004, p. 265-277.

FRIEDMAN, M. Introduction: Carnap's revolution in philosophy. In: (Friedman \& Creath, 2007), 2007.

. Reconsidering logical positivism. Cambridge: Cambridge University Press, 1999.

."The re-evaluation of logical positivism", in The journal of philosophy. Vol. 88, 1991,

p. 505-519.

FRIEDMAN, M. \& CREATH, R. (eds.). The Cambridge companion to Carnap. Cambridge:

Cambridge Press, 2007.

PEREIRA, R. A análise sintática e semântica da linguagem segundo Rudolf Carnap e Alfred

Tarski. Tese (doutorado em Filosofia). Universidade Federal de São Carlos. São Carlos, 16ıp., 2013.

QUINE, W. V. O. De um ponto de vista lógico: nove ensaios lógico-filosóficos. Tradução de Antonio Ianni Segatto. São Paulo: Editora Unesp, 2011. $2011 a$.

. Dois dogmas do empirismo. Tradução de Antonio Ianni Segatto. In: (Quine, 2011),

RICKETTS, T. Tolerance and logicism: logical syntax and the philosophy of mathematics. In: (Friedman \& Creath, 2007), 2007.

STEGMÜLLER, W. A filosofia contemporânea: introdução crítica. Tradução de Adaury Fiorotti e Edwino A. Royer. Rio de Janeiro: Forense Universitária. 2ª Edição, 2012.

. Mains currents in contemporany german, british, and American philosophy.

Translated by Albert E. Blumberg. Holland, Dordrecht: D. Reidel Publishing Company, 1969.

TARSKI, A. A concepção semântica da verdade: textos clássicos de Tarski. Cezar Augusto Mortari e Luiz Henrique de Araújo Dutra (orgs.). São Paulo: Editora UNESP, 2007.

. O conceito de verdade nas linguagens formalizadas. Tradução de Cezar A. Mortari.

In: (Tarski, 2007), 2007 .

TRANJAN, T. Carnap e a natureza da lógica. Tese (doutorado em filosofia). Universidade de São Paulo. São Paulo, 264p, 2010.

Submissão: 30.10.2018 / Aceite: 15.12.2018. 